\title{
Evaluation of drought and UV radiation impacts on above-ground biomass of mountain grassland by spectral reflectance and thermal imaging techniques
}

\author{
Kateřina Novotná, Karel Klem, Petr Holub, Barbora Rapantová, Otmar Urban \\ Global Change Research Institute CAS, Bèlidla 4a, Brno CZ-603 00, Czech Republic
}

\begin{abstract}
Novotná K., Klem K., Holub P., Rapantová B., Urban O. 2016: Evaluation of drought and UV radiation impacts on above-ground biomass of mountain grassland by spectral reflectance and thermal imaging techniques. - Beskydy, 9 (1-2): 2l-30

Drought represents one of the major factors limiting productivity of managed and natural ecosystems. Under natural field conditions drought is often associated with other stress factors such as high temperature and UV radiation, which may result in enhancement or vice versa alleviation of drought impact. Remote sensing methods have a large potential to evaluate impacts of drought on plant production at regional scale. The main objective of this study was to analyse the potential of ground-based measurement of spectral reflectance and thermal imaging for monitoring the impacts of drought and UV radiation on above-ground biomass production of mountain grassland ecosystem. Experimental rain-out shelters were used to manipulate incident precipitation and UV radiation for 7 weeks (May-July). A canopy spectral reflectance, thermal images, and total aboveground biomass were determined at the end of drought and UV treatment. Results show that drought led to a significant reduction of above-ground biomass, particularly under ambient UV radiation. In contrary, UV had only negligible effect on biomass production. Canopy temperature as well as selected spectral reflectance indices showed significant response to drought stress and also significant relationships to above-ground biomass. However, the relationship between canopy temperature and above-ground biomass is modified by UV radiation. Best prediction of changes in biomass caused by drought stress was provided by vegetation index NDVI.
\end{abstract}

Keywords: above-ground biomass, drought stress, grassland, UV radiation, precipitation, spectral reflectance, thermal imaging

\section{Introduction}

Altered rainfall patterns over a growing season are predicted under global climate change with reduced total amount of precipitation and redistributed rainfall into fewer but larger individual events (Easterling et al. 2000; Meehl et al. 2000; IPCC 2007). The results of a macro-scale water balance model show that in 2021-2030, water demand will increase world-wide due to the climate change (Tao et al. 2003). The effects of extreme weather events, such as drought or heavy rainfall, on biodiversity and ecosystem functioning are likely to be much stronger than the effects of changes in mean values of temperature and precipitation (Easterling et al. 2000; Meehl et al. 2000). Among the various responses of plants to drought, reduction in plant growth, which lead to reduction of leaf area for capturing sunlight and carrying out photosynthesis, has been found by a number of authors 
who attribute this to the high sensitivity of leaf expansion to leaf water status or cell turgor (e.g. Heckenberger et al. 1998). However, photosynthesis is also directly affected by stomatal and/or non-stomatal limitations under drought stress (Cornic 2000). Plants respond to drought stress through decreased stomatal conductance. However prolonged stomatal closure ultimately leads to a limitation of photosynthetic carbon assimilation and growth (Farquhar and Sharkey 1982). Furthermore, it causes changes in a number of physiological and biochemical processes governing plant growth and productivity (Daie 1988).

Although there are numerous experimental studies on evaluation impacts of drought stress on ecosystems (in grassland e.g. Frank 2007; Kreyling 2008) only few deals with interactions with other stress factors such as high temperature or UV radiation. Such interactions may alter the impacts of drought in different directions depending on intensity, timing, dynamics and also effects of other environmental factors. UV radiation can affect drought response through altered phytohormone metabolism and transport followed by changes in growth and plant morphology (reviewed by Robson et al. 2015), stomatal regulation (Jansen and van den Noort 2000) or antioxidant capacity (Agati et al. 2012).

Although several studies reported that UV radiation ameliorated plant sensitivity to drought (e.g. Alexieva et al. 2001; Poulson et al. 2006), other findings show synergistic interactions resulting in higher drought sensitivity under enhanced UV radiation (Petropoulou et al. 1995; Björn et al. 1997).

Due to a complexity of interactions with other factors which show high temporal and spatial variability is the estimation of drought impacts on productivity of ecosystems challenging. Remote sensing methods, particularly those based on infrared thermal imaging and spectral reflectance, have a potential to repeatedly detect drought effects on large areas. Thermal imaging detects particularly the changes in leaf temperature caused by stomata closure under drought stress (Grant et al. 2006). Under drought stress, the reduction of stomatal conductance leads to a limited transpiration and subsequent increase in leaf temperature. Thermal imaging is particularly well suited for detection of physiological response to drought under stable environmental conditions, because leaf temperature is beside transpiration rate dependent also on wind speed, air humidity and incident radiation (Jones et al. 2009). As the stomatal conductance can be also influenced by UV radiation (Jansen and van den Noort 2000), the results of detection drought responses by thermal imaging should be considered in relation to this factor. Although results of thermal imaging depend on a number of environmental conditions, and therefore requires constant conditions during measurement or normalization to given conditions, its main advantage is the possibility of early detection of drought responses.

On the contrary, spectral reflectance is based on biophysical parameters of canopy such as leaf area, biomass, chlorophyll or water content which are more stable in time and not directly affected by actual environmental conditions. The estimation of drought responses using spectral reflectance can be based on changes in biomass (NDVI, Aparicio et al. 2000), conversion of xanthophyll cycle carotenoids (PRI, Elsheery and Cao 2008), water content (WI, Peñuelas et al. 1997) or accumulation of oxidized phenolic compounds (BPI, Peñuelas et al. 2004). Spectral reflectance thus allows detection of different types of response, however, the interactions with other factors (e.g. nutrient availability, light conditions, canopy structure) can also significantly influence the results (Hatfield et al. 2008).

The main objective of this study was to evaluate the possibility of detection responses of mountain grassland to combined effect of drought stress and UV radiation using infrared thermal imaging and spectral reflectance. We hypothesized that thermal imaging results are more related to physiological status (stomatal conductance) and are therefore affected by both drought stress and UV radiation, whereas spectral reflectance data are mainly related to biomass which is primarily affected by drought.

\section{Materials and Methods}

The manipulation experiment, focused on the evaluation of combined effects of drought stress and UV radiation, was conducted in 2013 within the grassland ecosystem (association MolinioArrhenatheretea, class Polygono-Trisetion) at the experimental site Bílý Kř́žz, Moravian-Silesian Beskydy Mts. (altitude 890 m, latitude 49³0' $\mathrm{N}$, longitude $\left.18^{\circ} 32^{\prime} \mathrm{E}\right)$. The mean long-term annual temperature and precipitation are $6.8{ }^{\circ} \mathrm{C}$ 
and $1312 \mathrm{~mm}$, respectively. The vegetation season of 2013 was characterized as dry and slightly warmer, as the accumulated precipitation was only $59 \%$ of the long-term mean during vegetation season (March-July) and the temperatures were higher particularly in April and June by 1 and $0.6^{\circ} \mathrm{C}$ respectively (Tab. 1). The geological bedrock in experimental site is formed by Spodo-dystric cambisol on Flysch Godulian sandstone. The grassland is regularly cut once per growing season. The dominating grass species are Agrostis capillaris L. and Holcus mollis L. Dominating herb species is Hypericum maculatum Crantz.

Six experimental rain-out shelters (dimension $3 \times 2 \mathrm{~m}$ divided on two parts $1.5 \times 2 \mathrm{~m}$ with different UV treatment) were used for the manipulation of incident UV radiation and induction of drought stress. Shelters were formed by plastic lamellas enabling penetration of natural precipitations [Control] or their exclusion [Drought]. The lamellas (thickness of $3 \mathrm{~mm}$ ) were made from two types of acrylic material (Quinn Plastics, UK) each covering half of the shelter. The first one (UVT Solar) transmitted more than $90 \%$ of incident UV-A and UV-B radiation (UV+ treatment), whereas the second one (Quinn XT) filtered UV-B radiation and a large part of UV-A (UV- treatment). Thus 4 treatments were maintained: UV-[Control], UV+[Control], UV-[Drought], and UV+[Drought]. Each treatment was three times replicated, drought treatment fully randomized on experimental site and UV treatment arranged in split plot design. All treatments were applied for 7 weeks starting in early May. Volumetric soil water content, estimated regularly by a ThetaProbe ML2x (Delta-T, UK) at a depth of $15 \mathrm{~cm}$, was reduced at the end of experiment to approximately $56 \%$ in [Drought], whereas it was 100\% in [Control].
Measurement of spectral reflectance (350-2500 $\mathrm{nm}$ ) at the canopy level was carried out at the end of drought period (July 2nd) using a spectroradiometer FieldSpec 4 HiRes (ASD, USA). The measurements were conducted from a distance of ca $0.8 \mathrm{~m}$ using a pistol grip twice for each plot and then averaged. Subsequently, vegetation and chlorophyll indices were computed from spectral reflectance curves. Following 6 vegetation indices representing a diversity of spectral regions and having highest sensitivity to drought were selected ( $\mathrm{A}_{\lambda}$ refers to the reflectance at wavelength $\lambda$ in nanometres): ANMB $_{650-725}$ (Area under curve 650-725 nm normalised to maximal band depth; Malenovský et al. 2006); $S I P I=\left(R_{800}-R_{450}\right) /\left(R_{800}+R_{650}\right)$ (StructureIndependent Pigment Index; Peñuelas et al. 1995); NDVI $=\left(\mathrm{R}_{780}-\mathrm{R}_{670}\right) /\left(\mathrm{R}_{780}+\mathrm{R}_{670}\right)$ (Normalized Difference Vegetation Index; Rouse et al. 1973), $\mathrm{ZM}=\mathrm{R}_{750} / \mathrm{R}_{710}$ (Zarco-Tejada \& Miller index; Zarco-Tejada et al. 2001); WI/NDVI $=\left(\mathrm{R}_{900} / \mathrm{R}_{970}\right) /$ NDVI (Water Index normalized to NDVI; Piñol et al. 1998) and $\mathrm{G}=\mathrm{R}_{554} / \mathrm{R}_{677}$ (Greenness index; Smith et al. 1995). Thermal images were acquired around noon from a distance of ca $1 \mathrm{~m}$ using an infrared thermal camera SC 660 (Flir Systems, USA). For further analysis uncorrected values of canopy temperature were used. Approximately 100 points from each image were selected manually to avoid the effect of pixels from soil background.

The above-ground biomass was determined at the end of the experiment when the biomass reached a seasonal maximum. The area $0.3 \times 0.3 \mathrm{~m}$ was harvested per each plot. Plant material was separated into live and standing dead biomass, dried to a constant weight at $60^{\circ} \mathrm{C}$, and weighed.

Before the analysis of variance, the normality of data for individual parameters was tested using

Table 1: Monthly accumulated precipitations $(\mathrm{mm})$ and mean air temperatures in 2013 as compared with

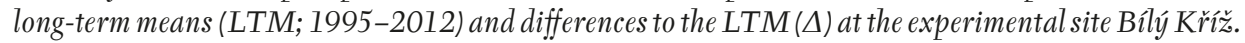

\begin{tabular}{l|ccccc}
\hline & March & April & May & June & July \\
\hline Precipitation 2013 (mm) & 71 & 33 & 135 & 111 & 40 \\
LTM 1995-2012 (mm) & 111 & 88 & 123 & 149 & 190 \\
$\Delta$ precipitation to LTM $(\mathbf{m m})$ & -40 & -55 & +12 & -38 & -150 \\
\hline Air temperature 2013 $\left({ }^{\circ} \mathbf{C}\right)$ & -2.6 & 6.8 & 11.4 & 14.9 & 16.0 \\
LTM 1995-2012 $\left({ }^{\circ} \mathbf{C}\right)$ & -0.1 & 5.8 & 11.2 & 14.3 & 16.1 \\
$\Delta$ temperature to LTM $\left({ }^{\circ} \mathbf{C}\right)$ & -2.5 & +1.0 & +0.2 & +0.6 & -0.1 \\
\hline
\end{tabular}


the Kolmogorov-Smirnov test. A two-way fixedeffect ANOVA model was used for the general analysis of drought stress and UV radiation effects. To compare the means, a two-way ANOVA followed by a multiple range test was performed to investigate the effects of drought stress and UV radiation on aboveground biomass, canopy temperature and reflectance parameters. Fisher's LSD post-hoc $(p \leq 0.05)$ test was used. Statistical tests were done using software Statistica 12 (StatSoft, USA).

\section{Results and Discussion}

As evident from Fig. 1 (left), above-ground biomass production was significantly reduced under [Drought] as compared to [Control]. On the contrary, the effect of UV radiation on the above-ground biomass was not statistically significant. It is, however, evident that UV radiation further modulated effect of drought. While biomass reduction under drought stress was $46 \%$ in UV-, this was ca $51 \%$ in UV+ treatment. This difference is mainly due to a positive effect of UV radiation on the production of above-ground biomass under sufficient water availability.

Grasslands represent one of the most vulnerable ecosystems to seasonal drought, particularly with regard to a low maximum rooting depth (Canadell et al. 1996). Rooting depth can be also limited in mountain grassland by shallow subsoil. Accordingly, Gilgen and Buchmann (2009) showed that above-ground biomass in mountain grassland is more affected by drought than in lowland grassland. Interactions between drought and UV radiation effects on aboveground biomass are not yet sufficiently understood. Some authors suggest an interaction between drought stress and UV radiation through flavonoid biosynthesis (Nogués et al. 1998). Flavonoids play an important role as antioxidants and can alleviate the oxidative stress induced by drought. For example Veselá et al. (2015) found enhanced accumulation of flavonoids under combined effect of drought and UV in grass as well as herb species. Drought tolerance can be also enhanced by effect of UV radiation on root development and an increase of root to shoot ratio (reviewed by Robson et al. 2015).

Thermal images proved that canopy temperature increases due drought and UV radiation (Fig. 1, right). The effect of UV radiation is, however, lower than drought effect and statistically insignificant. Under higher UV radiation the differences in canopy temperature between [Control] and [Drought] decreased. This interaction was mainly caused by higher temperature rise in the [Control] under higher UV intensity. These results indicate that UV generally stimulated stomatal closure, but this stimulation was higher in [Control] than [Drought]. The main effects on stomatal closure, however, has drought stress, which in UV - treatment rises the temperature by more than $6^{\circ} \mathrm{C}$ and in $\mathrm{UV}+$ treatment by more than $4^{\circ} \mathrm{C}$.

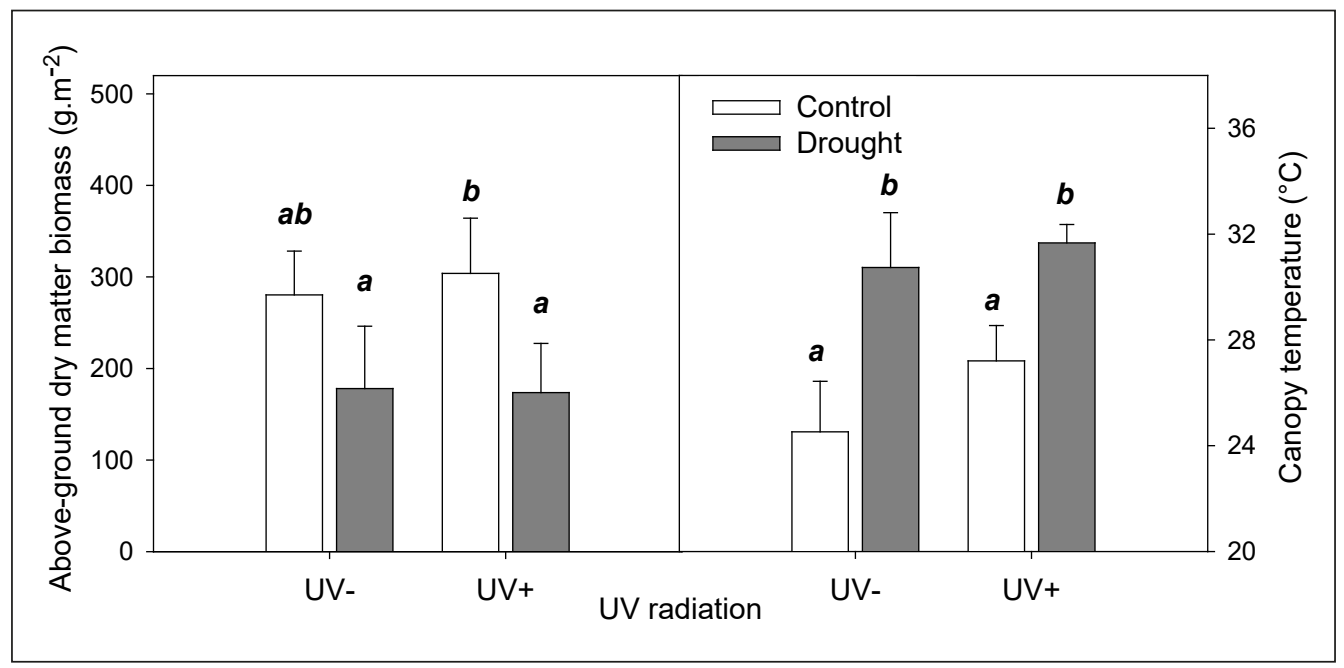

Fig. 1: The effect of drought and UV radiation on total above-ground dry matter biomass per ground area unit (left) and canopy temperature (right). Means (columns) and SD (error bars) are presented ( $n=3)$. Different letters denote statistically significant differences ( $p \leq 0.05)$ between treatments using Fisher's LSD post-hoc test. 
Thermal imaging represents one of the most promising methods for indirect and non-invasive estimation of stomatal conductance (Jones 1999). Estimation of stomatal conductance using thermal imaging can be very useful particularly for an early detection of drought stress. However, the final effect of drought on aboveground biomass can be different from stomatal response. Decline in stomatal conductance can be in short-term a sign of higher water use efficiency and thus lower response to drought stress, however, in long-term it means a severe drop in biomass productivity (Blum 2005). In addition, the complexity of thermal measurement of drought responses is also increased by the effects of some environmental factors such as wind speed, relative air humidity or incident radiation on stomatal conductance (Jones and Schofield 2008). Also our results show interactive effect of UV radiation and drought on canopy temperature (Fig. 3). This interaction indicates closing stomata in response to UV radiation, which was also found in a wide range of plant species (Nogués et al. 1998; Jansen and van den Noort 2000).

All the selected vegetation indices showed statistically significant responses to drought treatment, while these responses to UV radiation

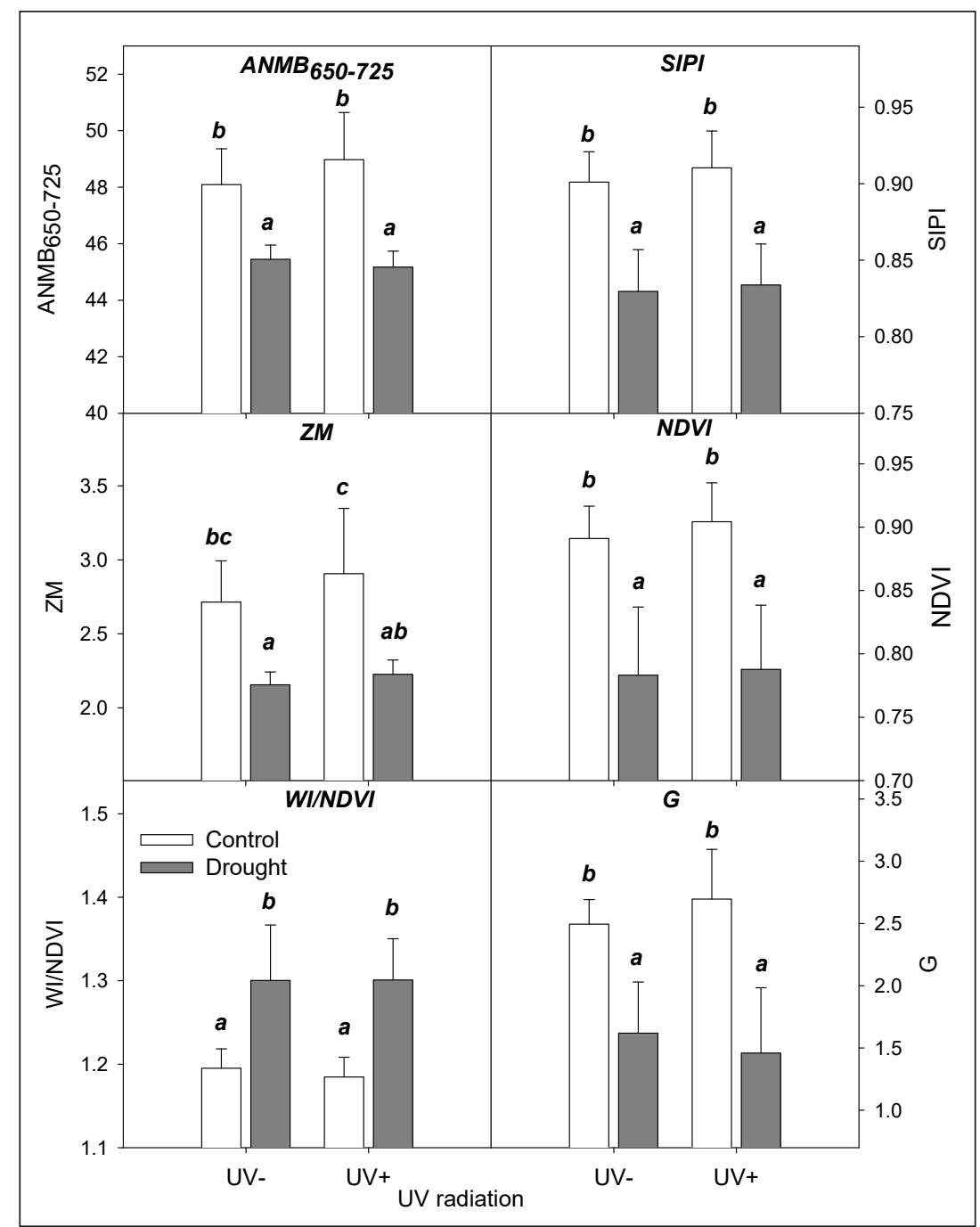

Fig. 2: The effect of drought and UV radiation on selected spectral reflectance parameters. Means (columns) and SD (error bars) are presented ( $n=3)$. Different letters denote statistically significant differences $(p \leq 0.05)$ between treatments using Fisher's LSD post-hoc test. 
were negligible (Fig. 2). Such relatively consistent response to drought stress was observed regardless the index is using reflectance from blue (carotenoids), green, red or red-edge (chlorophylls) and near infrared (water) bands. This is probably because the reflectance is strongly influenced by reduction in biomass (Fig. 1) and therefore changes in pigment composition are diminished by differences in biomass. Some trend in the effect of UV radiation on spectral reflectance data is apparent in indices using red-edge or green reflectance bands (ZM, ANMB ${ }_{650-725}$, G). These indices show increase under higher intensity of UV radiation for [Control] and very small decrease for [Drought] treatment (Fig. 2). Various authors reported different vegetation indices as most suitable for detection responses to drought stress. These include indices related to biomass or leaf area (NDVI, Aparicio et al. 2000), xanthophyll cycle carotenoids (PRI, Elsheery and Cao 2008), water content (WI, Peñuelas et al. 1997) or accumulation of oxidized phenolic compounds (BPI, Peñuelas et al. 2004). Such high diversity of indices sensitive to drought stress is probably caused by different stages and severity of drought stress within individual studies. While the change in the pigment composition indicates probably the early stress, changes in biomass production are already the result of severe and prolonged drought stress (Chaves et al. 2002). Significant changes in above-ground biomass under severe drought stress then are likely to mask the effect on pigment composition. This is also the case of our study where very similar responses were observed for different vegetation indices. However, the best results for estimation of above-ground biomass were achieved with NDVI index. Also other authors (e.g. Ji and Peters 2003) found that NDVI is an effective indicator of vegetation-water relationship.

Correlation analysis which have been conducted for spectral reflectance indices and aboveground biomass with data for each plot individually irrespective of UV and drought treatment, showed the highest correlation for index NDVI ( $R=0.90$; data not shown). Our results also show that NDVI is least affected by UV radiation as compared to other indices tested. No effect of UV radiation on vegetation indices was also confirmed by relationship between NDVI and above-ground biomass (Fig. 3, right). The separated linear relationships for UV- and $\mathrm{UV}+$ treatments show almost identical slopes with close relationships for both. On the contrary, relationships between canopy temperature and above-ground biomass (Fig. 3, left) are clearly separated by UV treatments. This results in reduction of Pearson correlation coefficients

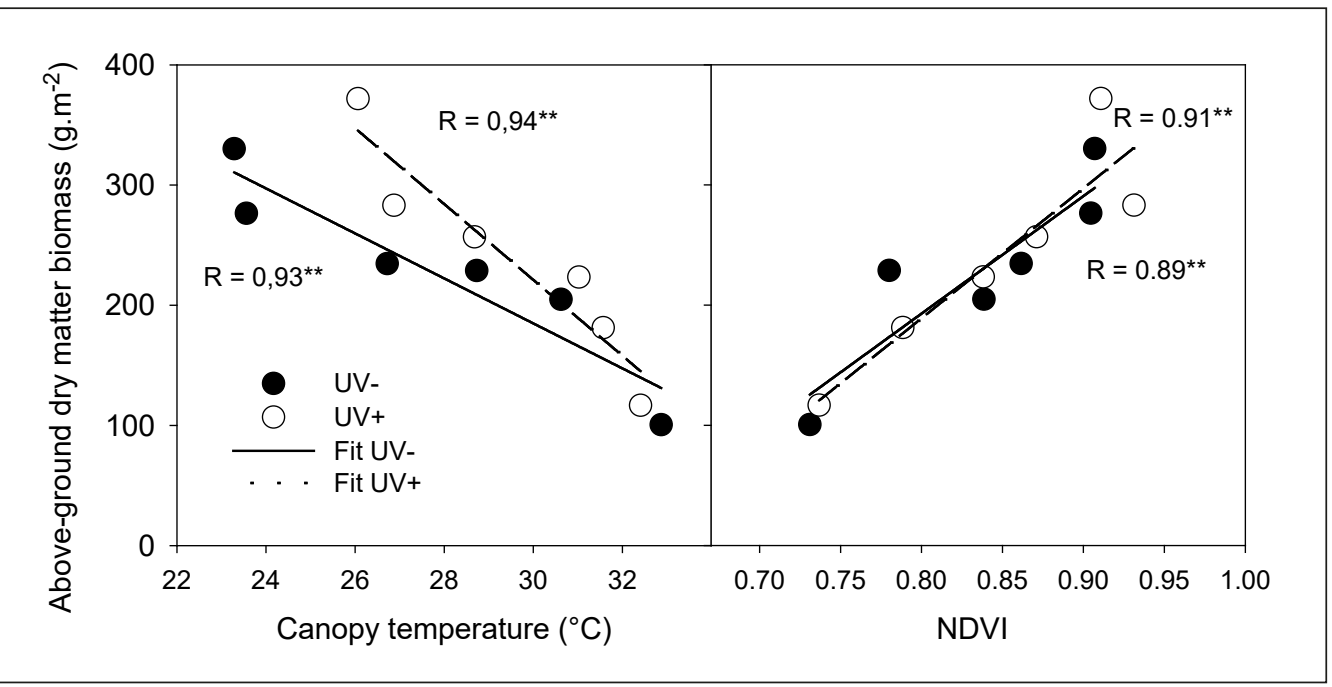

Fig. 3: Relationships between canopy temperature (left) or vegetation index NDVI (right) and above-ground biomass per ground area unit separately for excluded UV radiation (UV-, dark points) and ambient UV radiation (UV+, clear points). Points represent data from individual plots (replications). Pearson correlation coefficients $(R)$ are presented (**indicates statistically significant relationship at $p \leq 0.01)$. 
for whole dataset $(R=0.85)$ as compared to separated UV- and UV+ treatments. These results show that canopy temperature is affected by $\mathrm{UV}$ radiation and thus can modulate results of detection of drought responses. Effect of UV radiation on stomatal conductance was reported by Jansen and Noort (2000) who showed both stimulatory and also suppressive effect depending on light intensity. Similar interactions can be expected also in case of drought depending on drought severity. Our study suggests, that higher canopy temperature (indicating stomata closure) caused by UV radiation is not necessarily resulting in biomass reduction, which is the case of drought stress.

\section{Conclusions}

Drought stress during the main vegetation period (May-July) reduces significantly aboveground biomass production. No effect of UV radiation and also no interaction with drought stress on above-ground biomass were found. Both canopy temperature and spectral reflectance indices show similar response to drought stress as above-ground biomass. The best correlation to above-ground biomass was achieved for vegetation index NDVI. Relationship to canopy temperature shows separated lines for UV- and UV+ treatment, but also relatively high correlation to biomass. It can be concluded that both methods have potential for estimation of grassland responses to drought. Effects of other environmental factors such as UV radiation have to be, however, considered when thermal imaging is applied.

\section{Acknowledgement}

This work was supported by the Ministry of Education, Youth and Sports of CR within the National Sustainability Program I (NPU I), grant number LO1415.

\section{References}

Agati, G., Azzarello, E., Pollastri, S., TatTINI, M. 2012: Flavonoids as antioxidants in plants: Location and functional significance. Plant Science, 196: 67-76.

Alexieva, V., Sergiev, I., Mapelli, S., Karanov, E. 2001: The effect of drought and ultraviolet radiation on growth and stress markers in pea and wheat. Plant Cell and Environment, 24: 1337-1344.

Aparicio, N., Villegas, D., Casadesus, J., Araus, J.L., Royo, C. 2000: Spectral vegetation indices as nondestructive tools for determining durum wheat yield. Agronomy Journal, 92: 83-91.

Björn, L.O., Callaghan, T.V., Johnsen, I., Lee, J.A., Manetas, Y., Paul, N.D., Sonesson, M., Wellburn, A.R., Coop, D., Heide-Jorgensen, H.S., Gehrke, C., Gwynn-Jones, D., Johanson, U., Kyparissis, A., Levizou, E., Nikolopoulos, D., Petropoulou, Y., Stephanou, M. 1997: The effects of UV-B radiation on European heathland species. Plant Ecology, 128: 253-264.

Blum, A. 2005: Drought resistance, wateruse efficiency, and yield potential - are they compatible, dissonant, or mutually exclusive? Australian Journal of Agricultural Research, 56: 1159-1168.

Canadell, J., Jackson, R.B., Ehleringer, J.R., Mooney, H.A., Sala, O.E., Schulze, E.D. 1996: Maximum rooting depth of vegetation types at the global scale. Oecologia, 108: 583-595.

Chaves, M.M., Pereira, J.S., Maroco, J., Rodriguez, M.L., Ricardo, C.P.P., Osorio, M.L., Carvalho, I., Faria, T., Pinheiro, C. 2002: How plants cope with water stress in the field. Photosynthesis and growth. Annals of Botany, 89: 907-916.

Cornic, G. 2000: Drought stress inhibits photosynthesis by decreasing stomatal aperture-not by affecting ATP synthesis. Trends in Plant Science, 5: 187-188.

DAIE, J. 1988: Mechanism of drought-induced alterations in assimilate partitioning and transport in crops. CRC Critical Reviews in Plant Science, 7: 117-137.

Easterling, D.R., Meehl, G.A., Parmesan, C., Changnon, S.A., Karl, T.R., Mearns, L.O. 2000: Climate extremes: Observations, modeling, and impacts. Science, 289: 2068-2074.

Elsheery, N.I., CAO, K.F. 2008: Gas exchange, chlorophyll fluorescence, and osmotic adjustment in two mango cultivars under drought stress. Acta Physiologiae Plantarum, 30: 769-777.

Farquhar, G.D., Sharkey, T.D. 1982: Stomatal conductance and photosynthesis. Annual Review of Plant Physiology and Plant Molecular Biology, 33: 317-345. 
Frank, D.A. 2007: Drought effect on aboveand belowground production of a grazed temperate grassland ecosystem. Oecologia, 152: 131-139.

Gilgen, A.K., Buchmann, N. 2009: Response of temperate grasslands at different altitudes to simulated summer drought differed but scaled with annual precipitation. Biogeoscience, 6: 2525-2539.

Grant, O.M., Chaves, M.M., Jones, H.G. 2006: Optimizing thermal imaging as a technique for detecting stomatal closure induced by drought stress under greenhouse conditions. Physiologia Plantarum, 127: 507-518.

Hatfield, J.L., Gitelson, A.A., Schepers, J.S., Walthall, C.L. 2008: Application of spectral remote sensing for agronomic decisions. Agronomy Journal, 100: 117-131.

Heckenberger, U., Roggatz, U., Schurr, U. 1998: Effect of drought stress on the cytological status in Ricinus communis. Journal of Experimental Botany, 49: 181-189.

IPCC 2007: Climate Change 2007. The Physical Science Basis. Intergovernmental Panel on Climate Change, Geneva.

Jansen, M.A.K., van den Noort, R.E. 2000: Ultraviolet-B radiation induces complex alterations in stomatal behaviour. Physiologia Plantarum, 110: 189-194.

Ji, L., Peters, A.J. 2003: Assessing vegetation response to drought in the northern Great Plains using vegetation and drought indices. Remote Sensing of Environment, 87: 85-98.

Jones, H.G. 1999: Use of thermography for quantitative studies of spatial and temporal variation of stomatal conductance over leaf surfaces. Plant Cell and Environment, 22: 1043-1055.

Jones, H.G., Schofield, P. 2008: Thermal and other remote sensing of plant stress. General and Applied Plant Physiology, 34: 19-32.

Jones, H.G., SerraJ, R., Loveys, B.R., Xiong, L.Z., Wheaton, A., Price, A.H. 2009: Thermal infrared imaging of crop canopies for the remote diagnosis and quantification of plant responses to water stress in the field. Functional Plant Biology, 36: 978-989.

Kreyling, J., Wenigmann, M., Beierkuhnlein, C., Jentsch, A. 2008: Effect of extreme weather events on plant productivity and tissue dieback are modified by community composition. Ecosystems, 11: 752-763.
Malenovský, Z., Ufer, C., Lhotáková, Z., Clevers, J.G.P.W., Schaepman, M.E., Albrechtová, J., Cudlín, P. 2006: A new hyperspectral index for chlorophyll estimation of a forest canopy: Area under curve normalised to maximal band depth between 650-725 $\mathrm{nm}$. EARSeL eProceedings, 5: 161-172.

Meehl, G.A., Washington, W.M., Arblaster, J.M., Bettge, T.W., Strand, W.G. 2000: Anthropogenic forcing and decadal climate variability in sensitivity experiments of twentieth- and twenty-first-century climate. Journal of Climate, 13: 3728-3744.

Nogués, S., Allen, D.J., Morison, J.I.L., BaKer, N.R. 1998: Ultraviolet-B radiation effects on water relations, leaf development, and photosynthesis in droughted pea plants. Plant Physiology, 117: 173-181.

Peñuelas, J., Baret, F., Filella, I. 1995: Semi-empirical indices. Photosynthetica, 31: 221-230.

Peñuelas, J., Pinol, J., Ogaya, R., Filella, I. 1997: Estimation of plant water concentration by the reflectance Water Index WI (R900/ R970). International Journal of Remote Sensing, 18:2869-2875.

Peñuelas, J., Munné-Bosch, S., Llusià, J., Filella, I. 2004: Leaf reflectance and photoand antioxidant protection in field-grown summer-stressed Phillyrea angustifolia. Optical signals of oxidative stress? New Phytologist, 162: 115-124.

Petropoulou, Y., Kyparissis, A., Nikolopoulos, D., Manetas, Y. 1995: Enhanced UV-B radiation alleviates the adverse-effects of summer drought in 2 mediterranean pines under field conditions. Physiologia Plantarum, 94: 37-44.

Piñol, J., Filella, I., Ogaya, R., Peñuelas, J. 1998: Ground-based spectroradiometric estimation of live fine fuel moisture of Mediterranean plants. Agricultural and Forest Meteorology, 90: 173-186.

Poulson, M.E., Boeger, M.R.T., Donahue, R.A. 2006: Response of photosynthesis to high light and drought for Arabidopsis thaliana grown under a UV-B enhanced light regime. Photosynthesis Research, 90: 79-90.

Robson, T.M., Klem, K., Urban, O., Jansen, M.A.K. 2015: Re-interpreting plant morphological responses to UV-B radiation. Plant Cell and Environment, 38: 856-866.

Rouse, J.W., HaAs, R.H., Schell, J.A., Deering D.W. 1973: Monitoring vegetation systems in 
the Great Plains with ERTS. In: Third ERTS Symposium, NASA SP-351, Vol. 1, NASA, Washington, DC, 309-317.

Smith, R.C.G., Adams, J., Stephens, D.J., Hick, P.T. 1995: Forecasting wheat yield in a Mediterranean-type environment from the NOAA satellite. Australian Journal of Agricultural Research, 46: 113-125.

TaO, F.L., Yokozawa, M., Hayashi, Y., Lin, E. 2003: Terrestrial water cycle and the impact of climate change. Ambio, 32: 295-301.

Veselá, B., Novotná, K., Rajsnerová, P., Klem, K., Holub., P., Urban, O. 2015: Interactive effects of UV radiation and drought on the accumulation of flavonols in selected herbs and grass in a mountain grassland ecosystem. In: Urban, O., Šprtová, M., Klem, K. (eds): Global Change: A Complex Challenge, Brno, 102-105.

Zarco-Tejada, P.J., Miller, J.R., Noland, T.L., Mohammed, G.H., Sampson, P.H. 2001: Scaling-up and model inversion methods with narrowband optical indices for chlorophyll content estimation in closed forest canopies with hyperspectral data. IEEE Transactions on Geoscience and Remote Sensing, 39: 1491-1507. 